https://dx.doi.org/10.4314/ijs.v20i2.19

Ife Journal of Science vol. 20, no. 2 (2018)

\title{
FLUTED PUMPKIN [Telfaria occidentalis (HOOK F.)]: GENETIC DIVERSITY AND LANDRACE IDENTIFICATION USING PHENOTYPIC TRAITS AND RAPD MARKERS
}

\author{
Adeyemo, O. A. ${ }^{1 *}$ and Tijani, H. A. \\ ${ }^{1}$ Department of Cell Biology and Genetics, University of Lagos, Akoka, Lagos, Nigeria \\ *E-mail address of corresponding author: aoadeyemo@unilag.edu.ng; adeyemonik@yahoo.co.uk
}

(Received: $29^{\text {th }}$ March, 2018; Accepted: 14 ${ }^{\text {th }}$ June, 2018)

\section{ABSTRACT}

Fluted pumpkin [Telfaria occidentalis (Hook F.)] is a nutritious tropical vegetable crop. Genetic diversity was evaluated in a collected set of Telfairia occidentalis Hook F. landraces. Various phenotypic traits were examined in a total of 23 landraces and a subset of 12 landraces. Data analysis revealed that considerable variation observed in the 23 fluted pumpkin landraces was in the fruit weight. The 12 landraces had moderate variation in total chlorophyll and carotene contents whereas low variation was observed in leaf length and width. Twelve subset fluted pumpkin landraces were genotyped using 10 selected Random Amplified DNA polymorphism (RAPD) markers. The number of alleles detected per marker ranged from 3 to 5, with a total of 40 alleles. The mean percentage polymorphic loci observed was 56.8. All primers had low resolving power (Rp) with a mean of 0.85 . Genetic similarity values ranged from 0.63 and 0.88 with a mean of 0.76 . The Dice coefficient genetic similarity using unweighted pair group method using arithmetic averages (UPGMA) grouped the 12 landraces in 2 (groups I and II) according to extent of genetic relationship among the analysed fluted pumpkin landraces. Similar groupings were projected in the principal component analysis (PCA). The lines PUE05 and PUI09 are closely related and they also exhibited farthest genetic distance from the other landraces in both the UPGMA and PCA. These results show that more effort should be geared towards genetic conservation of Telfairia occidentalis Hook F.

Keywords: Telfaria occidentalis (Hook F.)], Genetic diversity, Landraces identification, Phenotypic traits, RAPD markers

\section{INTRODUCTION}

Fluted pumpkin [Telfaria occidentalis (Hook F.)] is a tropical vine crop that belongs to the family Cucurbitaceae grown in almost all the agroecological zones of Nigeria mainly for its edible leafy vegetable (Akoroda, 1990; Schippers 2002). It has been suggested that Imo state in southeastern Nigeria is the centre of fluted pumpkin's origin where it has the widest diversity such as variation in pod and seed characteristics, plant vigour, leaf size and succulence (Uguru and Onovo 2011). It is cultivated in West Africa for diverse uses such as for economic, nutritional and medicinal benefits. The seed is rich in oil and protein. The leaf serves as a source of protein, magnesium, iron, phytic acid, tannins, vitamins, minerals and the leaf fibre is commonly used in the cure of diabetes and anaemia (Akwaowo et al., 2000). The leaves contain $11 \%$ crude protein, $28 \%$ carbohydrate, $3 \%$ oil, $11 \%$ ash and $700 \mathrm{ppm}$ of iron (Oyolu, 1978). Fluted pumpkin waste has the potential for improving compost nutrient quality of organic manure (Soyingbe et al., 2012). It has also been reported that it can be used in bioremediation of heavy metal- polluted soil (Obute et al., 2001).

The diverse phenotypic characters of fluted pumpkin could provide basis for phenotypic characterisation of the landraces. The fruits of fluted pumpkin are large, containing ovoid seeds which are up to about $5 \mathrm{~cm}$ long and are usually dark brown or reddish brown in colour varying from about $500 \mathrm{~g}$ to $1850 \mathrm{~g}$ of seeds per pod. The plant can produce between 10-200 seeds per fruit depending on the size of the fruit and 2-5 fruits per plant. The fruits are marked by conspicuous longitudinal ridges mostly pale green in colour and can weigh between $2-10 \mathrm{~kg}$ at maturity, up to $85 \mathrm{~cm}$ in diameter and $75 \mathrm{~cm}$ in length. It has a yellowish ripe epicarp and the fruit pulp is a fibrous orange or yellow colour (Okoli and Mbgeogu, 1983). Considerable variation was observed among 35 genotypes of fluted pumpkin for ten agronomic characters studied (Fayeun et al., 2012).

Genetic diversity of a given collection can be based on phenotypic traits (Fayeun et al., 2016). 
However, they are often highly susceptible to environmental variation. Moreover, it is important to use molecular analysis as a powerful and complementary technique to know the genetic relationship among a set of closely related cultivated genotypes of fluted pumpkin Molecular markers have been proven to be a reliable method for genotyping collection of cucurbit accessions because RAPD alleles are generated across the whole genome, this makes them to be advantageous (Gwanama, et al., 2000; Dey et al., 2006). RAPD markers have been conveniently employed for various molecular plant genetic diversity analysis such as in the identification of similar varieties and characterization of genotypes. These markers have also been reported for estimating genetic relatedness; they have the advantages of simplicity and has great utility to detect relatively small amounts of genetic variation (Skroch et al., 1995).

The genetic differences among the fluted pumpkin genotypes based on morphological and AFLP markers have been reported (Ndukwu et al., 2005). The identification of ISSR primers for genetic analysis of fluted pumpkin has also been analysed (Sakpere, 2011). There are comparatively few studies on the genetic diversity within traditional fluted pumpkin landraces reported recently using molecular techniques. There is increased rapid cultivation of traditional local fluted pumpkin by farmers in Nigeria which might lead to ample genetic diversity. The knowledge of information concerning landrace identification and genetic variability level of the fluted pumpkin is limited. On this account, the study of genetic diversity of fluted pumpkin will facilitate their identification and characterisation of genetic resources for its efficient conservation and future exploitation. Therefore, the objective of this study was to assess the genetic diversity among a collection of traditional fluted pumpkin landraces from selected areas where they are grown in Nigeria using phenotypic traits and RAPD markers.

\section{Plant Materials}

Fruits of twenty three individual fluted pumpkin were obtained from 3 agro-ecological locations (South-eastern, South-western and South-south states) of Nigeria and were used for the study
(Table 1).

\section{Phenotypic Traits Measured in Collected Fruits}

In the laboratory, each fruit collected was used to classify 10 fruit qualitative traits [the fruit colour, shape, ridge, neck, mouth, flesh colour, length $(\mathrm{cm})$, fruit centre width $(\mathrm{cm})$ and weight $(\mathrm{g})]$ of each landrace (Tables 2 and 3). The fruit pod was opened and the seeds were carefully separated from the flesh of the different landraces of fluted pumpkin to evaluate the seed colour, number of seeds per fruit and number of seeds compartment per fruit. Fruit fresh weights were determined using a conventional scale and lengths were measured using a graduated metre ruler and tape rule.

\section{Phenotypic Characterisation Measured in Subset}

After the above phenotypic characterisations, 12 landraces of fluted pumpkin of the 23 previous set, a representative of the fruit variability were used to study four leaf characteristics. Seeds from the 12 landraces were germinated in plastic containers. After six weeks of planting, the maximum leaf width and length $(\mathrm{cm})$ of each landrace were measured. The total chlorophyll and carotenoid contents in 12 landraces of fluted pumpkin leaves were also determined according to the procedures by Arnon (1949) and Lichtenthaler and Wellburn (1983). About $100 \mathrm{mg}$ of fluted pumpkin fresh leaf tissues were weighed and soaked in $10 \mathrm{ml}$ of dimethyl sulfoxide (DMSO): acetone mixture (1:1) for extraction for 15 mins. Analyses of samples were done using a spectrophotometer. The absorbance of acetone extracts was measured at 663, 645 and $470 \mathrm{~nm}$.

All analyses were done in triplicates. All phenotypic diversity used were according to the standards of the descriptor list documented by the Biodiversity International for Cucurbitaceace (2007).

\section{Molecular Analysis}

In RAPD analysis, a subset of twelve of Telfairia occidentalis Hook F. landraces was used. The genomic DNA was isolated from fresh young leaf tissues of about 4-6 seedlings per landrace sampled in bulk using the CTAB method with minor modifications (Doyle and Doyle, 1987). 
DNA concentration and quality were determined using a Nano drop spectrophotometer. The DNA concentration was measured at $260 \mathrm{~nm}$, while the ratio of readings at $260 \mathrm{~nm} / 280 \mathrm{~nm}$ was used to estimate the DNA quality.

The genotyping of landraces was employed with RAPD markers (OPB, OPH and OPT) comprising of 12 decamer random primers (Operon Technologies, Alameda, CA, USA). Firstly, optimization of PCR conditions for RAPD primers were standardized for good amplifications using a subset of 3 landraces. PCR amplifications were performed in PCR mixture $(10 \mu \mathrm{l})$ which contained 100 ng of genomic DNA as template, 10x PCR buffer, $2.5 \mathrm{mM}$ DNTPs, 50 $\mathrm{mM} \mathrm{MgCl}, 5$ unit (U) of Taq DNA polymerase and 5 pMol of each primer. PCR was performed using a thermal cycler at initial temperature of 94 ${ }^{\circ} \mathrm{C}$ for 5 mins, followed by 40 cycles at $94^{\circ} \mathrm{C}$ for 1 $\min , 38^{\circ} \mathrm{C}$ for $\mathrm{Imin}$, and $72^{\circ} \mathrm{C}$ for 5 mins.

PCR products obtained were separated on $1.5 \%$ agarose gel, stained with ethidium-bromide and visualized using Gel documentation unit (BIORAD, USA) connected to a PC. The size of amplicons was estimated from 100 bp standard molecular weight DNA marker.

\section{Phenotypic Data Analysis}

Seven fruit qualitative traits were subjected to analysis using Kruskal-Wallis non-parametric test in SPSS 16.0 (SPSS, 2007) while other data were analysed using descriptive statistics. Values for mean, standard deviation (SD), maximum, minimum and coefficient of variation $(\mathrm{CV})$ were calculated for each of the 5 and 3 phenotypic characters evaluated in the 23 and subset 12 landraces respectively. Coefficients of variation were used as indicators of variability. Total chlorophyll and carotenoid contents were calculated using the equations provided by Lichtenthaler and Welburn (1983).

\section{Analysis of Genetic Parameters \\ Amplicons of each allele were scored as "1" (present) and " 0 " as absent. The binary matrix was used to generate genetic similarity among landraces based on the Dice coefficient of similarity/dissimilarity (Nei and Li, 1979) using the Numerical Taxonomy and. Multivariate Analysis (NTSYSpc) version 2.11S (Exeter Software, Setauket, NY, USA) program. The}

generated similarity matrix was then used for the construction of a dendrogram using the UPGMA clustering method. To further identify genetic relatedness among the landraces, a principal component analysis (PCA) was produced. Observed number of allele per locus, percentage of polymorphic loci and total allele generated were manually calculated. Resolving power (Rp) which is the ability of each primer to detect level of variation between individuals was done (Prevost and Wilkinson, 1999).

$\mathrm{Rp}=\Sigma \mathrm{Ib}$ where Ib (band informativeness)

takes the values of:

$$
1-(2 *[0.5-p])
$$

where $\mathrm{p}$ is the proportion of individuals containing the band.

\section{RESULTS}

\section{Phenotypic Variation in Fruit Traits, Total Chlorophyll and Carotene Contents, Leaf Length and Width}

Qualitative fruit traits among the 23 fluted pumpkin landraces are presented in table 3 . The common fruit colour was medium green colour among 12 landraces, while only 5 had dark green and the rest were light green in colour (30\%). Most landraces exhibited ellipsoid fruit shape while very few showed clavate (17\%), narrowly obovate $(9 \%)$, pyriform (4\%) and rhomboidal (17\%) fruit shapes (Table 3). Fruit ridges were either flat or deep. Nineteen landraces (83\%) had fruit necks but absent in four (17\%). Fourteen landraces $(61 \%)$ possessed slightly woody fruit texture whereas nine landraces $(39 \%)$ had woody texture. Also, fourteen landraces $(61 \%)$ exhibited pointed fruit mouth and nine (39\%) showed curved mouth. Sixteen landraces $(70 \%)$ manifested orange fruit flesh colour while seven (30\%) displayed yellow fruit flesh colour. Plate 1 shows pictures of some of the fruit shapes. KruskalWallis non-parametric test revealed that the fluted pumpkin landraces had no significant differences (Chi-squared $=22, \mathrm{df}=2, \mathrm{p}>0.05$ ) with respect to the seven fruit qualitative traits assessed (Table 3).

Table 4 summarises the 5 phenotypic characters evaluated in the 23 landraces. Variations in some 
phenotypic traits between landraces were varied considerably. The results showed that the fruit weight among the genotypes had a large variation with variation coefficient (CV) of 54.28.

Low variations were observed in fruit length, fruit centre width and number of seed compartment per fruit (CV = 12.66, 18.09 and 15.5, respectively). The fruit weight ranged from 2.12 to $10.10 \mathrm{~kg}$ while the fruit length varied from $34-73 \mathrm{~cm}$. The average total number of seeds/per fruit found was 81.04. The summary of 4 phenotypic characters evaluated among the 12 landraces are presented in table 5. The values of $\mathrm{CV}$ displayed in table 5 indicate moderate variation in total chlorophyll content and carotene content $(\mathrm{CV}=51.64$ and 52.17 respectively), however, low variation was observed in leaf length and width among the 12 landraces.

\section{RAPD Diversity Analyses}

Genetic diversity was detected among the 12 fluted pumpkin landraces using RAPD analysis. All the twelve decamer primers amplified in all the lines tested but only 10 primers demonstrated polymorphism (Table 6). The 12 RAPD primers yielded a total of 40 alleles. The average number of alleles per locus was 3.33, OPB10 and OPT06 having five, 4 primers four, 4 loci (3) and two having 1 allele. Of the 40 alleles scored with the 12 primers, the percentage polymorphic loci observed was 56.8, indicating a very moderate polymorphism. The resolving power (Rp) of the polymorphic loci ranged from 0.17 for primer OPH05 to 2.17 for primer OPT06. All primers had low $\mathrm{Rp}$ with a mean of 0.85 , indicating their inability to completely distinguish between landraces.

Genetic similarity among lines ranged from 0.63 and 0.88 with a mean of 0.76 , showing that they did not differ largely. Figure 1 shows a cluster analysis based on the matrix of Dice coefficient genetic similarity using UPGMA grouped the 12 landraces to 2 groups (I and II) according to extent of genetic relationship among the analysed fluted pumpkin landraces. Two subgroups were further separated in the group II. The group I consisted of 8 landraces from four states, indicating that they are more genetically similar while 4 landraces made up group II, but the level of variation was very low. Similar groupings were projected in the principal component analysis (PCA) (Figure 2) which showed a relative relationship between the places of collection and genetic diversity. The landraces can be distinguished using the first PCA1 and second PCA2 which showed 18.59\% and $22.48 \%$ respectively and this cumulatively account for $41.07 \%$ of the variation in the RAPD data. The majority of landraces from the southeast were grouped with 2 landraces from south south together in the PC1 and PC2 while the two landraces (PUO08 and PUL07) grown in the south west and another 2 landraces (PUE05 and PUI09) form distinct distances from the remaining 8 landraces forming outliers. Thus, the difference was clearly observed among the landraces. Landraces PUE05 and PUI09 are closely related and also exhibited the furthest genetic distance from the other landraces in both the UPGMA and PCA (Figures 1 and 2).

\section{DISCUSSION}

This study focused on the diversity analyses among and within a collected set of fluted pumpkin (Telfairia occidentalis Hook F.) landraces. The evaluation of a total of 23 landraces of fluted pumpkins revealed phenotypic differences in fruit sizes, shapes, while pointed fruit mouth was predominant and the fruit flesh colour showed only two types of colour (yellow and orange) in the present results. Also, variability of other phenotypic characters evaluated among the 23 landraces such as the fruit length, fruit centre width, and number of seeds compartment per fruit showed low variation among them, however, the CV was high for the fruit weight. In the morphological assessments of the seed traits, seed colours were light brown, light dark brown and reddish brown colour (data not presented). Furthermore, moderate variation was found in other phenotypic traits such as the total chlorophyll and carotene contents whereas low variation was observed in leaf length and width in the subset of 12 landraces. The results of this study detected considerable level of phenotypic diversity for some phenotypic characters among the sets of fluted pumpkin landraces, revealing genetic differences. This might be due to selection by farmers and the varied environmental conditions where the pumpkins were collected. Earlier, Fayeun et al. (2016) reported genetic variability among 21 fluted pumpkins for seedling 
traits. Morphological differences are commonly reported among cucurbits (Mladenovic et al., 2012).

In this study of RAPD analysis in 12 landraces, percentage of polymorphism (56.80\%) among the fluted pumpkin showed by RAPD markers was relatively low. This indicates that there is a fair amount of variation among the landraces. It may be attributed to the use of the low number of primers or the close genetic relatedness of the studied landraces. The analysis of genetic similarity using the RAPD markers revealed that the 12 fluted pumpkin landraces were divided into two main groups, the second group of 8 landraces was further divided into 2 sub-groups. The dendrogram grouping indicated relationship between the geographical areas and the genetic diversity to some extent. In this study, three out of the four landraces of fluted pumpkin collected from Imo State belonged to group I (PUI10, PUI11 and PUI12), while the two varieties from Anambra State revealed close genetic relatedness to group I. The group (GII), however, consisted of landraces collected from 3 geographical regions. In a study by Ndukwu et al. (2005), they reported two groups formed by 30 strains of fluted pumpkins genotyped by AFLP markers and also observed close genetic relations among them. The PCA obtained using RAPD results clearly identified the most significant landraces; however, it exhibited a grouping of the fluted pumpkin landraces comparable to the UGPMA analysis. The present RAPD result suggests considerably its usefulness in landrace identification and detection of the genetic variations present in the closely related twelve (12) fluted pumpkin landraces studied at the molecular level.

It is noteworthy that the RAPD markers revealed genetic relationships among the landraces. However, a high level of similarity was observed within all landraces that clustered together in the two groups which was in accordance with the considerable morphological similarities observed among the landraces in this study, which could be an evidence of loss of genetic diversity of most of the landraces. Other study of genetic diversity in Curcurbita moschata, a close relative of fluted pumpkin found low genetic variation among 31 tropical pumpkin accessions investigated by 16 RAPD markers (Gwanama et al., 2000). In addition, evaluation in 50 of Asian bitter gourd (Momordica charantia L.) accessions using 17 RAPD markers produced 84 amplicons, of which 33 (41.34\%) were found polymorphic with genetic distances (GD) ranged from 0.03 to 0.28 (Dalamu et al., 2012).

Finally, the variations in the phenotypic traits and RAPD assessments suggest that they can be used undoubtedly to estimate the genetic diversity and relatedness among the different fluted pumpkins germplasm landraces and a necessity for proper management and conservation strategies of genetic resources. Future studies are needed that will evaluate additional fluted pumpkins from diverse locations in Nigeria to assess genetic diversity for conservation. The transferability of some cucurbits SSR makers can also be used to provide more useful information regarding fluted pumpkin genetic diversity between agro-climatic

Table 1: List of Fluted Pumpkin Landraces Used in the Study and States of

\begin{tabular}{llllll}
\multicolumn{2}{l}{ Collection Sites } & & Code & State & Town \\
\hline PUA01 & Abia & Umuahia (Utoro) & PUA13 & Abia & Ohunhun \\
PUB02 & Anambra & Obah & PUA14 & Abia & Ohunhun \\
PUB03 & Anambra & Onitsha & PUA15 & Abia & Ohunhun \\
PUE04 & Edo & Benin & PUA16 & Abia & Umuahia \\
PUE05 & Edo & Okale & PUS17 & Osun & - \\
PUE06 & Edo & - & PUG18 & Ogun & - \\
PUL07 & Lagos & Lagos & PUC19 & Calabar & Ikot Ekpene \\
PUO08 & Ogun & - & PUC20 & Calabar & Eket \\
PU109 & Imo & Emekuku & PUE21 & Edo & - \\
PU10 & Imo & Enyiogugu Aboh Mbaije & PUD22 & Ondo & Ore \\
PUI1 & Imo & Ikeduru & PUN23 & Anambra & - \\
PU112 & Imo & Ahiazu-Mbaise & & & \\
\hline
\end{tabular}


396 Adeyemo and Tijani: Fluted Pumpkin [Telfaria occidentalis ]: Genetic Diversity and Landrace Identification

Table 2: List of Qualitative Fruit Traits with Description used for Genetic Diversity Analysis Among Fluted Pumpkin Landraces

\begin{tabular}{ll}
\hline Qualitative traits & Description \\
\hline Fruit colour (FC) & $1=$ light green, $2=$ medium green, $3=$ dark green \\
Fruit shape (FS) & $1=$ ellipsoid, $2=$ narrowly obovate, $3=$ rhomboidal, $4=$ clavate, $5=$ pyriform \\
Fruit ridge (FR) & $1=$ flat, $2=$ deep \\
Fruit neck (FN) & $1=$ present, $0=$ absent \\
Fruit texture (FT) & $1=$ woody, $2=$ non woody \\
Fruit mouth (FM) & $1=$ pointed, $2=$ curved \\
Fruit flesh colour (FFC) & $1=$ orange, $2=$ yellow \\
\hline
\end{tabular}

Table 3: Phenotypic Variation in Fruit Qualitative Traits Among Fluted Pumpkin Landraces

\begin{tabular}{|c|c|c|c|c|c|c|c|}
\hline Code & FC & FS & FR & FN & FT & FM & FFC \\
\hline PUA01 & Light Green & Ellipsoid & Flat & Present & Slightly Woody & Pointed & Orange \\
\hline PUB02 & Medium Green & Narrowly Obovate & Deep & Present & Woody & Pointed & Orange \\
\hline PUB03 & Light Green & Narrowly Obovate & Flat & Present & Woody & Curved & Orange \\
\hline PUE04 & Light Green & Ellipsoid & Deep & Present & Slightly Woody & Pointed & Orange \\
\hline PUE05 & Medium Green & Ellipsoid & Flat & Present & Slightly Woody & Pointed & Orange \\
\hline PUE06 & Dark Green & Ellipsoid & Flat & Present & Woody & Curved & Orange \\
\hline PUL07 & Light Green & Ellipsoid & Flat & Present & Slightly Woody & Curved & Yellow \\
\hline PUO08 & Light Green & Ellipsoid & Deep & Absent & Slightly Woody & Pointed & Orange \\
\hline PUI09 & Medium Green & Ellipsoid & Flat & Present & Woody & Curved & Orange \\
\hline PUI10 & Light Green & Ellipsoid & Flat & Absent & Slightly Woody & Pointed & Orange \\
\hline PUI11 & Dark Green & Ellipsoid & Deep & Present & Woody & Curved & Yellow \\
\hline PUI12 & Medium Green & Ellipsoid & Flat & Present & Slightly Woody & Curved & Orange \\
\hline PUA13 & Medium Green & Ellipsoid & Flat & Absent & Slightly Woody & Pointed & Orange \\
\hline PUA14 & Light Green & Pyriform & Flat & Present & Slightly Woody & Curved & Orange \\
\hline PUA15 & Medium Green & Ellipsoid & Flat & Absent & Slightly Woody & Pointed & Yellow \\
\hline PUA16 & Medium Green & Clavate & Deep & Present & Slightly Woody & Pointed & Orange \\
\hline PUS17 & Dark Green & Rhomboidal & Flat & Present & Slightly Woody & Pointed & Yellow \\
\hline PUG18 & Dark Green & Clavate & Deep & Present & Woody & Pointed & Orange \\
\hline PUC19 & Medium Green & Clavate & Flat & Present & Slightly Woody & Curved & Yellow \\
\hline PUC20 & Medium Green & Clavate & Deep & Present & Slightly Woody & Pointed & Yellow \\
\hline PUE21 & Medium Green & Rhomboidal & Flat & Present & Woody & Pointed & Yellow \\
\hline PUD22 & Medium Green & Rhomboidal & Flat & Present & Woody & Curved & Orange \\
\hline PUN23 & Dark Green & Rhomboidal & Flat & Present & Woody & Pointed & Orange \\
\hline KWSL & 0.45 & 0.45 & 0.45 & 0.45 & 0.45 & 0.45 & 0.45 \\
\hline
\end{tabular}

Fruit colour (FC), Fruit shape, Fruit ridge (FR), Fruit neck (FN), Fruit texture (FT), Fruit mouth (FM), Fruit flesh colour (FFC).

Table 4: Descriptive Statistics for Fruit and Seed Traits (Each character was evaluated among 23 landraces of fluted pumpkin)

\begin{tabular}{lccccc}
\hline Character & & & & & \\
Cumulative contribution & Mean & SD & Max & Min & CV (\%) \\
\hline Fruit length (cm) & 52.47 & 11.36 & 73.50 & 34.00 & 21.66 \\
Fruit centre width (cm) & 62.78 & 11.35 & 86.00 & 49.50 & 18.09 \\
Fruit weight (kg) & 4.42 & 2.40 & 10.10 & 2.12 & 54.28 \\
Total number of seeds / per fruit & 81.04 & 30.12 & 127.00 & 18.00 & 37.17 \\
Number of seed compartment per fruit & 5.35 & 0.83 & 6.00 & 4.00 & 15.55 \\
\hline
\end{tabular}


Table 5: Descriptive Statistics of Leaf Traits (Each character was evaluated among 12 landraces of fluted pumpkin)

\begin{tabular}{lccccc}
\hline Character & & & & & \\
Cumulative contribution & Mean & SD & Max & Min & CV (\%) \\
\hline Total chlorophyll content $(\mu \mathrm{mol} / \mathrm{ml})$ & 3.82 & 1.97 & 7.53 & 1.35 & 51.64 \\
Carotene content $(\mu \mathrm{mol} / \mathrm{ml})$ & 291.40 & 152.03 & 606.78 & 108.95 & 52.17 \\
Leaf length $(\mathrm{cm})$ & 9.28 & 1.18 & 12.13 & 7.73 & 12.72 \\
Leaf width $(\mathrm{cm})$ & 4.54 & 1.65 & 9.73 & 3.57 & 36.41 \\
\hline
\end{tabular}

Table 6: Number of Alleles, Percentage of Polymorphic Alleles and Resolving Power of RAPDMarkers

\begin{tabular}{clcccc}
\hline Serial no & Markers & Na & PL & PPL & Rp \\
\hline 1 & OPB10 & 5 & 3 & 60 & 1.5 \\
2 & OPB12 & 4 & 4 & 100 & 1 \\
3 & OPB13 & 3 & 2 & 66.67 & 0.5 \\
4 & OPH02 & 4 & 4 & 100 & 1.5 \\
5 & OPH04 & 3 & 0 & 0 & 0 \\
6 & OPH05 & 3 & 1 & 33.33 & 0.17 \\
7 & OPT01 & 4 & 4 & 100 & 1.33 \\
8 & OPT04 & 4 & 3 & 75 & 1.67 \\
9 & OPT06 & 5 & 4 & 80 & 2.17 \\
10 & OPT07 & 1 & 0 & 0 & 0 \\
11 & OPT20 & 3 & 2 & 66.67 & 0.67 \\
12 & OPT17 & 1 & 0 & 0 & 0 \\
\hline Total & 40 & 27 & & \\
\hline Mean & 3.3 & 3 & 56.8 & 0.85 \\
\hline Na: number of observed alleles; PL: polymorphic loci \\
PPL: Percentage polymorphic loci; Rp: resolving power
\end{tabular}


398 Adeyemo and Tijani: Fluted Pumpkin [Telfaria occidentalis ]: Genetic Diversity and Landrace Identification

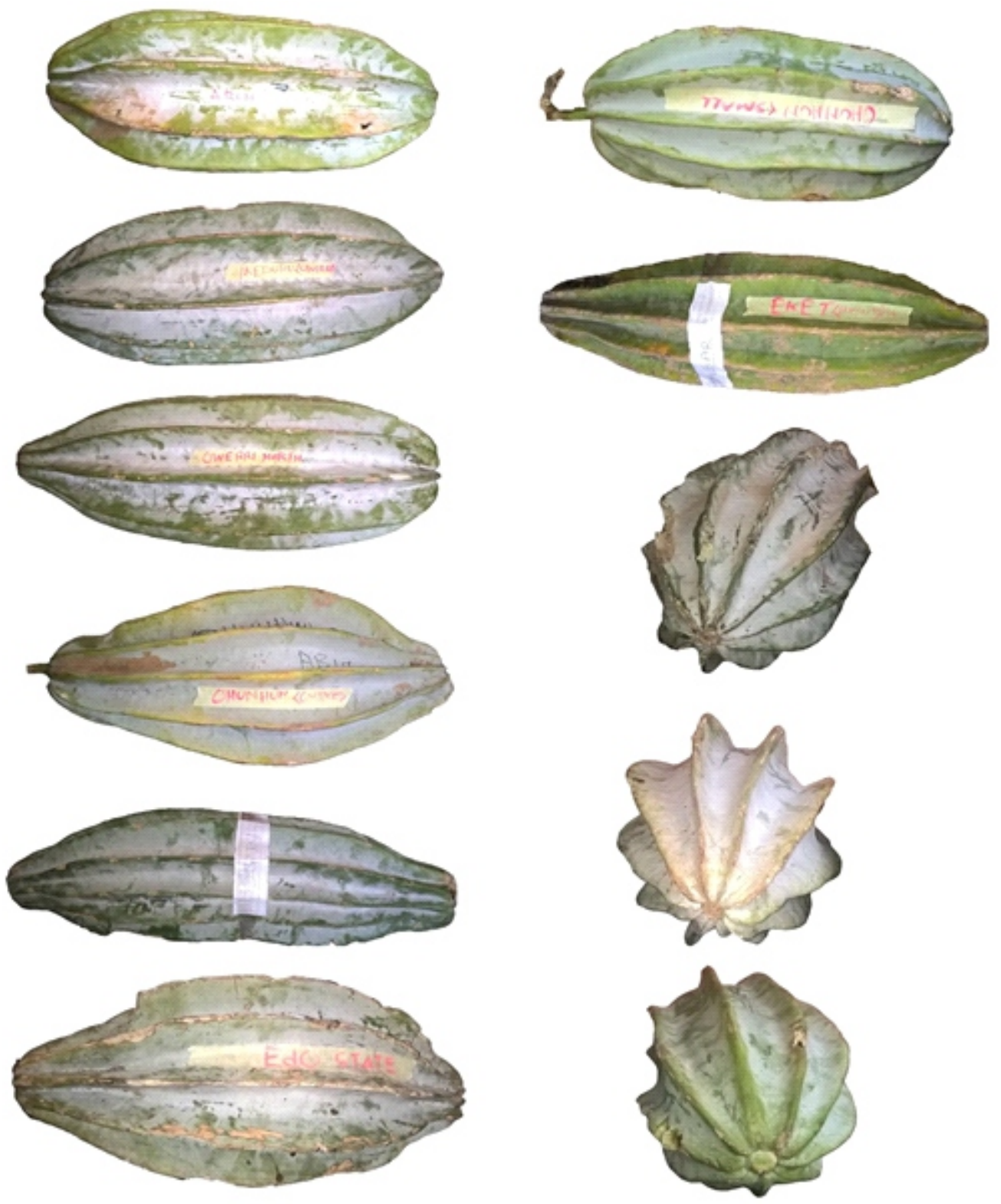

Plate 1. Picture of the Diversity in Fruit Size and Shape for Telfairia occidentalis Hook F. Landraces used in the Study 


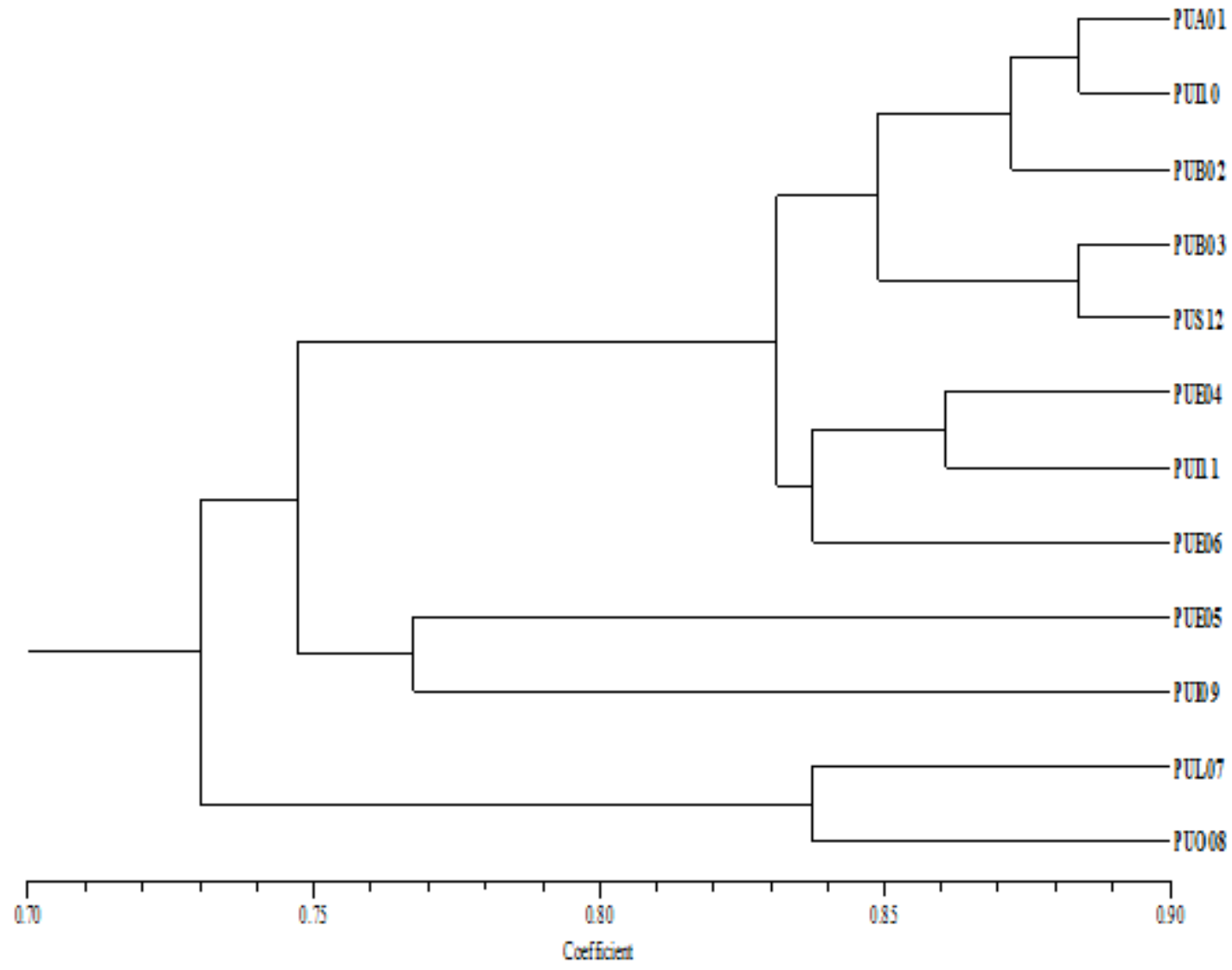

Figure 1. Dendrogram of Cluster Analysis among 12 Fluted Pumpkin Landraces based on RAPD Data using UPGMA Method based on Dice Coefficient of Similarity

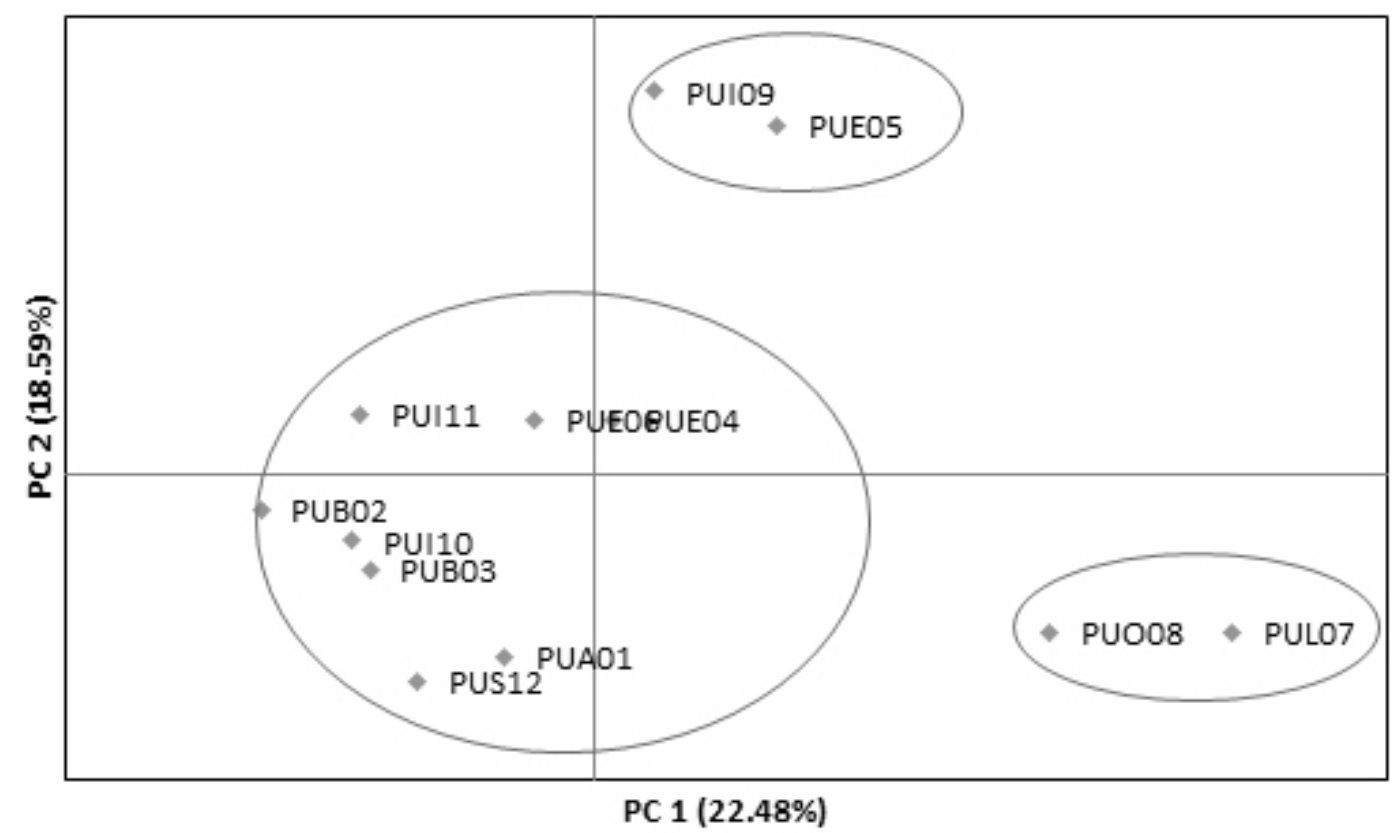

Figure 2: PCA Plot Showing the Distribution of 12 Fluted Pumpkin Landraces Constructed Using on Dice Coefficient of Similarity Based on RAPD Data 


\section{REFERENCES}

Akoroda, M. O. (1990). Ethno botany of Telfairia occidentalis (cucurbitaceae) among Ibos of

Nigeria. Economic Botany. 44:29-39.

Akwaowo, E.U., Ndon, B. A. and Etuk, E. U. (2000). Minerals and antinutrients in fluted pumpkin (Telfairia occidentalis. Hook. F). Food Chemistry. 70(2): 235- 240.

Arnon, D. (1949). Copper enzymes in isolated chloroplasts. Polyphenoloxidase in Beta vulgaris. Plant Physiology. 24:1-15.

Dalamu, T. K., Behera, Gaikwad, A. B., Saxena, S., Bharadwaj, C. and Munshi, A. D. (2012). Morphological and molecular analyses define the genetic diversity of Asian bitter gourd (Momordica charantia L.) Australian Journal of Crop Science. 6(2):261-267.

Dey, S.S., Singh, A.K., Chandel, D. and Behera, T.K., (2006). Genetic diversity of bitter gourd (Momordica charantia L.) genotypes revealed by RAPD markers and agronomic traits. Scientia Horticulturae. 109: 21-28.

Doyle, J.J. and Doyle, J.L. (1987). A rapid procedure for DNA purification from small quantities of fresh leaf tissue. PhytochemicalBulletin. 19:11-15.

Fayeun, L. S., Odiyi, A.C. and Adetunji, O. (2012). Comparative study of growth parameters and marketable leaf yield of the fluted pumpkin (Telfairia occidentalis Hook.F.) genotypes collected from seven southern Nigerian states. Scholarly Journal of Agricultural Science. 2(8): 157-162.

Fayeun, L.S., Hammed, L.A., Oduwaye, O.A., Madike, J.U. and Ushie, E.U. (2016). Estimates of Genetic Variability for Seedling Traits in Fluted Pumpkin (Telfairia occidentalis Hook. F). Plant Breeding and Biotechnology. 4(2):262 270.

Gwanama, M.T. Labuschagne, M.T. and Botha, A.M. (2000). Analysis of genetic variation in Cucurbita moschata by random amplified polymorphic DNA (RAPD) markers Euphytica. 113: 19-24.

Lichtenthaler, H. K. and Wellburn, A.R. (1983). Determinations of total carotenoids and chlorophylls a and b of leaf extracts in different solvents. Biochemical Society Transactions. 11: 591-592.

Mladenovic, E., Berenji, J., Ognjanov, J.B.V.,
Ljubojevic, M. and Cukanovic, J. (2012). Genetic variability of bottle gourd (Lagenaria siceraria (Mol.) Standley and its morphological characterization by multivariate analysis. Archives of Biological Sciences, (Belgrade). 64: 573-583.

Ndukwu, B.C., Obute, G. C. and Wary-Toby, I. L. (2005). Tracking sexual dimorphism in Telfairia occidentalis Hooker F. (Cucurbitaceae) with morphological and molecular markers. African Journal of Biotechnology. 4 (11): 1245-1249.

Nei, M. and Li, W.H. (1979). Mathematical model for studying genetic variation in terms of restriction endonucleases. Proceedings of the National Academy of Sciences of the USA. 76 : 5269-5273.

Obute, G.C., Wegwu, M.O. and Akaninwor J.O. (2001). Determination of Lead accumulation and Toxicity in Telfairia occidentalis Hook F. (Cucurbitaceae) in the Niger Delta. Journal of Applied Sciences and EnvironmentalManagement. 5: 85-88.

Okoli, B.E. and Mgbeogwu, C. M. (1983): Fluted Pumpkin Telfairia occidentalis, West African Vegetable Crops. Economic Botany. 3(2): 145-149.

Oyolu, C. (1978). Relatively unknown vegetables: Fluted pumpkin (Telfairia occidentalis). Proceedings of the Annual Conference of Horticultural Society of Nigeria. 1:106-177.

Prevost, A. and M. J. Wilkinson. (1999). A new system of comparing PCR primers applied to ISSR fingerprinting of potato cultivars. Theoretical and Applied Genetics. 98: 107-112.

Sakpere, A. M. (2011). Identification of ISSR Primers for Genetic Analysis of Telfairia Occidentalis Hook F. Ife Journal of Science. 13(1):129-131.

Schippers, R. R. (2002). African Indigenous Vegetables: An Overview of the Cultivated Species. Revised Ed. Natural Resources International Limited, Aylesford, United Kingdom. 214pp

Skroch, R.J., Ronning, C.M. and Knight, R.J. (1995). Qualitative and quantitative characterization of RAPD variation among snap bean (Phaseolus vulgaris) genotypes. Theoretical and Applied Genetics. 91:1078-1085. 
Soyingbe, A. A., Hammed, T.B., Rosiji, C.O. and Adeyemi, J.K. (2012). Evaluation of fluted pumpkin (Telfairia occidentalis, Hook F.) waste as nutrient amendment in compost for its effective management and crop production. IOSR Journal of Environmental Science, Toxicology and Food Technology. 1:3238.
Statistical Analysis System (SAS). (2000). Online Doc. Version 9.0. Cary, NC, SAS Institute Inc.

Uguru, M.I. and J.C. Onovo. (2011). Evidence of polyploidy in fluted pumpkin (Telfairia occidentalis Hook F.). African Journal of Plant Science. 5 (5): 287-290. 